Revue de l'Institut des langues et cultures

d'Europe, Amérique, Afrique, Asie et Australie

$45 \mid 2022$

Femme(s) et sorcellerie en Espagne et en Italie à l'époque moderne

\title{
Sapos vestidos y murciélagos muertos: magia de género en la temprana Edad Moderna
}

Dead Bats and Dressed Toads: Gendered Magic in Early Modern Spain

Crapauds habillés et chauves-souris mortes : magie de genre à l'époque moderne

\section{María Tausiet}

\section{OpenEdition}

Journals

Edición electrónica

URL: https://journals.openedition.org/ilcea/14654

DOI: $10.4000 /$ ilcea.14654

ISSN: 2101-0609

Editor

UGA Éditions/Université Grenoble Alpes

Edición impresa

ISBN: 978-2-37747-330-4

ISSN: $1639-6073$

Referencia electrónica

María Tausiet, «Sapos vestidos y murciélagos muertos: magia de género en la temprana Edad

Moderna», ILCEA [En línea], 45 | 2022, Publicado el 31 enero 2022, consultado el 31 enero 2022. URL:

http://journals.openedition.org/ilcea/14654 ; DOI: https://doi.org/10.4000/ilcea.14654

Este documento fue generado automáticamente el 31 enero 2022.

(c) ILCEA 


\section{Sapos vestidos y murciélagos muertos: magia de género en la temprana Edad Moderna}

Dead Bats and Dressed Toads: Gendered Magic in Early Modern Spain

Crapauds habillés et chauves-souris mortes : magie de genre à l'époque moderne

\section{María Tausiet}

¡Que todos los hechizos de Sycorax, apos, escarabajos y murciélagos, caigan sobre ti! ${ }^{1}$

En torno al caldero dad vueltas y vueltas,

Y en él arrojad la víscera infecta. Que hierva primero el sapo que cría Y suda veneno por treinta y un días Yaciendo dormido debajo de rocas: Que sea cocido en la mágica olla².

I

1 Dos de los animales mencionados más frecuentemente en los procesos por brujería y superstición de la Edad Moderna son sapos y murciélagos. Los primeros se asociaban fundamentalmente a las mujeres (brujas) y los segundos a los hombres (magos o hechiceros). Esta distinción, aparentemente casual, basada en prácticas reales, pero sobre todo en significados simbólicos, revela una indudable aproximación de género al mundo de las creencias (Breuer, 2009). En contraste con el carácter maléfico atribuido a los sapos y a la brujería femenina, el uso de murciélagos por parte de los varones acusados de nigromancia apunta a una visión positiva de la magia, vista como un arte o ciencia capaz de hacer posible lo imposible. 
Figura 1. - Francisco de Goya, «Contra el bien general» (Desastres de la Guerra, número 71).

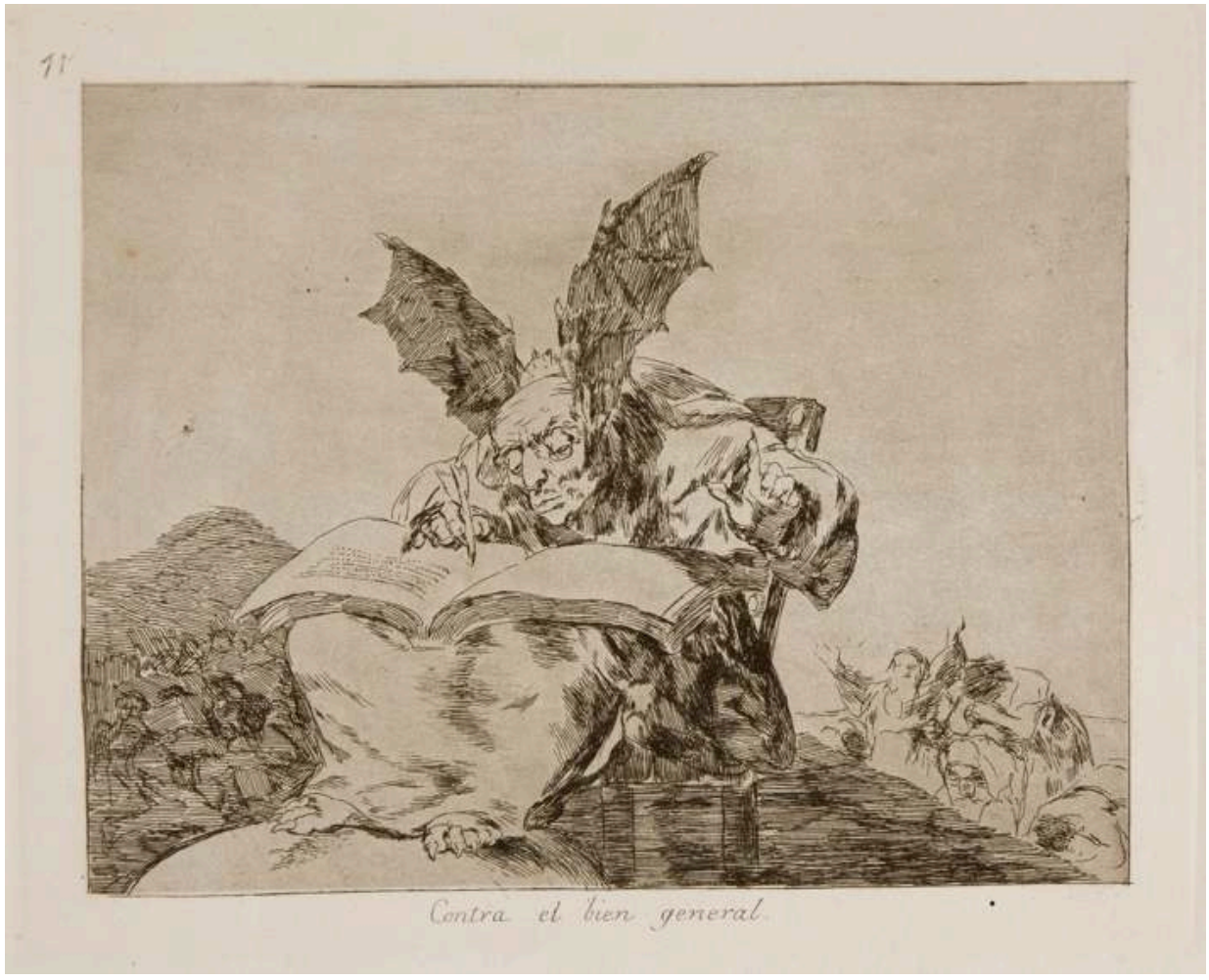

2 Más allá de la utilización de ambos animales en determinados conjuros y hechizos, resulta interesante tratar de entender la filosofía y el sistema de correspondencias que les sirve de base. En las antiguas culturas rurales la estrecha convivencia de los seres humanos con el mundo natural (animales, plantas, minerales) implicaba un fuerte sentimiento de parentesco, en especial con determinadas especies de animales y plantas. Tal y como han estudiado algunos antropólogos en relación con el llamado totemismo ${ }^{3}$, solo a partir de la revolución industrial la frontera entre el hombre y el resto de seres vivos empezó a dibujarse drásticamente.

La cercanía que ciertas comunidades e individuos sentían respecto a determinados animales llevó en muchos casos a copiar sus gestos y costumbres. Como escribió Marius Schneider, «la imitación [...] constituye la base de casi toda la actividad espiritual y material primitiva» y «únicamente puede realizarse desde la simpatía». Según el mitólogo, el equivalente de la «revelación divina» de las altas culturas equivaldría a la «imitación exacta» en el mundo primitivo:

Imitar con exactitud es hacerse espejo del objeto $\mathrm{y}$, con eso, hasta cierto punto, ser el objeto mismo. Pero 'llegar a ser el objeto mismo' equivale a conocerlo. Así, tanto la revelación divina como la imitación exacta son formas del conocer. (Schneider, 1998: 30-31)

La imitación de los animales conllevaba una suerte de identificación con ellos. No es de extrañar, por tanto, que ciertas especies se vieran como encarnación de los espíritus de los antepasados, con el tiempo convertidos en divinidades, tanto positivas como negativas. Dentro del amplio grupo de animales simbólicos -reales y fabulosos al mismo tiempo, cargados de especial significación mágica $y$, en cierto modo, representantes de polos opuestos- sobresalen los sapos y los murciélagos. 
A diferencia de lo que sucede en otras civilizaciones, en la cultura cristiana los reptiles -serpientes, lagartos - y batracios -sapos y ranas - fueron vistos desde muy pronto como símbolo viviente de lo más repugnante y execrable. Algunos animales - perros, gatos, cerdos- compartían una gran intimidad con el hombre; otros -bovinos, ovinos, caprinos, equinos- se consideraban como miembros de la familia, aunque algo más lejanos; un tercer grupo -el de la fauna salvaje- no suscitaba sentimientos demasiado intensos, con excepción del astuto lobo, enemigo por excelencia tanto del ganado como de los seres humanos. En cambio, todo lo que se arrastraba «con el vientre por los suelos» era «detestado, temido y despreciado» (Le Roy Ladurie, 1988: 431).

No obstante, como señaló Emmanuel Le Roy Ladurie, la repulsión por los reptiles y batracios convivía paradójicamente con la atribución a dichos animales de un aura misteriosa, de modo que fueron utilizados para representar «la intimidad más secreta del yo humano» (1988:432). Ello se hace palpable en algunos relatos fantásticos referidos al vuelo mágico al país de los muertos. Según estas narraciones, el espíritu o alma de ciertos soñantes se alojaría en un pequeño animal -a menudo un sapo o lagarto-, abandonaba sus cuerpos por uno de sus orificios - normalmente la boca- y volvía a introducirse en sus poseedores cargado de conocimientos iniciáticos (Le Roy Ladurie, 1984: 258-261; Ginzburg, 1991).

7 Desde finales de la Edad Media, los batracios -sapos y ranas, no siempre fácilmente distinguibles entre sí- se asociaron a la mitología de la brujería y en particular a la psicología femenina. En el caso de las mujeres dormidas que viajaban en sueños a un más allá imaginario, su doble o alter ego se encarnaba por lo común en un sapo o una araña que salía y entraba a través de su vagina (Charuty, 1997: 82-94). Dicha posesión espiritual -como la de la venenosa tarántula que dio lugar al fenómeno del tarantismo - implicaba una mordedura en los órganos genitales femeninos (De Martino, 1999; Pizza, 1998). La íntima relación entre las mujeres y tales animales se manifestó doblemente, pues estos últimos no sólo se visualizaban introduciéndose en el cuerpo femenino, sino que, en el caso de los sapos, llegaron incluso a identificarse con el útero mismo. En ese sentido, resulta llamativo que uno de los relatos incluidos por el jesuita español Martín del Río en sus célebres Disquisiciones mágicas describa la aparición de un sapo saltando sobre el vientre de una joven en el momento del parto, justo antes de dar a luz a su criatura (Del Río, 1599-1600).

8 La representación del útero en forma de sapo se basaba en tradiciones procedentes de la Antigüedad grecorromana, según las cuales la matriz se concebía como un órgano dotado de movilidad, lo que la haría similar a un animal que habitara o poseyera el cuerpo femenino (Pizza, 2001). Con el cristianismo, la capacidad «histérica» atribuida a las mujeres se asoció a ciertos movimientos rápidos y convulsivos como los saltos del sapo, cuya mordedura, según muchas alegorías medievales, simbolizaba el deseo sexual. No hay que olvidar que, tanto en las artes plásticas como en la literatura, este animal de piel pegajosa, siempre lubrificada, representaba, junto con la serpiente, el pecado de la lujuria, atribuido fundamentalmente a la mujer. Haciendo gala de un profundo sexismo, Francisco de Quevedo reflejó en su Sueño del infierno dicho lugar común en una grotesca visión del sexo femenino (Rodríguez Cacho, 2012), en la que una muchedumbre de 
ranas ridículas encarnaba a las mujeres casadas, ejemplificando de ese modo su horripilante lascivia:

Topé con una laguna muy grande como el mar, y más sucia, adonde era tanto el ruido, que se me desvanecía la cabeza. Pregunté lo que era aquello, y dijéronme que allí penaban las mujeres que en el mundo se volvieron en dueñas. Así supe cómo las dueñas de acá son ranas del infierno, que eternamente como ranas están hablando, sin ton y sin son, húmedas y en cieno, y son propiamente ranas infernales. Porque las dueñas ni son carne ni pescado, como ellas. Dióme grande risa el verlas convertidas en sabandijas tan perniabiertas y que no se comen sino de medio abajo, como la dueña, cuya cara siempre es trabajosa y arrugada. (Quevedo, 1972: 153)

Desde el siglo xv en adelante, la asociación entre los batracios y la sexualidad femenina se plasmó en una serie de tratados teológicos acerca de la maldad intrínseca de las mujeres en general y de las brujas en particular. Según un buen número de demonólogos, los sapos constituían una de las más frecuentes metamorfosis animales de las brujas. La comunión espiritual entre el diablo y sus cómplices se manifestaría asimismo en la marca corporal dejada por Satanás en éstas como signo visible del pacto y de la intimidad física entre ambos (Delpech, 1993). Los estigmas del diablo solían localizarse en la espalda de las acusadas -cualquier mancha o verruga servía como pretexto-, provocando su pretendida insensibilidad al dolor. Pero, en ocasiones, se afirmaba también que tales señales eran visibles en la pupila de las mujeres que eran brujas, donde podía observarse la figura de un sapo en miniatura o, al menos una pata de este (De Graaf, 1991).

Sin duda, la región europea en la que el sapo alcanzó un mayor protagonismo durante el período de la «caza de brujas» fue el País Vasco-Navarro, en sus vertientes tanto francesa como española. Ya desde comienzos del siglo Xvi se conservan en esta región testimonios de la marca ocular que supuestamente servía para reconocer a los secuaces del diablo. Según la declaración hecha en 1595 por Juana de Baráibar - una muchacha de doce o trece años con fama de catadora de brujos-, la señal «a manera de zarpa de sapo en el ojo izquierdo» que su madre le había enseñado a distinguir desde muy niña era indeleble, y sólo podían verla quienes eran brujos a su vez

Dicho mito aparecía especialmente desarrollado en el informe sobre el célebre proceso contra los brujos de Zugarramurdi. Tal y como escribió Juan de Mongastón acerca del auto de fe que tuvo lugar en Logroño en $1610^{5}$, lo primero que hacían quienes renegaban de la fe cristiana y se convertían en brujos era adorar al demonio besándole en varias partes de su cuerpo, incluidas las partes pudendas, tras lo cual este les hacía una marca o herida con la uña de la que salía sangre,

[...] y después, en la niñeta de los ojos, con una cosa caliente, como si fuese de oro, les marca (sin dolor) un sapillo que sirve de señal con que se conocen los unos a los otros. (1989: 40)

12 Según el juez Pierre de Lancre, la misma creencia estaba extendida en el País VascoFrancés. Durante los procesos de brujería que él mismo instruyó en 1609 en la región de Labort,

[...] una muchacha que simulaba conocer a todos los brujos y brujas al primer golpe de vista, nos dijo que todas las brujas de Biarritz estaban marcadas en el ojo izquierdo, con una marca parecida a una pata de sapo, lo que las brujas de esa localidad que confesaban corroboraban. (Lancre, 2004: 59)

13 La figura del sapo no sólo servía como expresión del alma de los brujos -en su mayoría mujeres. Dicha faceta espiritual se complementaba con otra estrictamente práctica, ya 
que, según muchos testimonios, los sapos eran utilizados como ingredientes de un buen número de hechizos. Según relataba el juez Pierre de Lancre, Marie de la Ralde, una mujer de veintiocho años, declaró haber asistido a un buen número de aquelarres desde muy niña y

[...] afirmó que había visto cómo algunas brujas atrapaban sapos a dentelladas para luego desollarlos y apilarlos, sin saber qué hacían después con ellos. (2004: 116)

Corroborando dicha creencia, Marie de Aspilcoutte, una adolescente de diecinueve años, aseguró que algunos de los asistentes al aquelarre

[...] se dedican a cortar la cabeza a los sapos, mientras los demás fabrican veneno; que este se hace tanto en casa como en el sabbat, con sapos, con la semillas, la corteza y la médula de un arbusto [...] que vulgarmente es llamado el árbol de las brujas [y que] también utilizan en su elaboración pequeñas culebras y arañas. (Ibíd.: 117)

15 De acuerdo con Lancre, la muchacha habría explicado que la sustancia venenosa segregada por los sapos era utilizada por los practicantes de la brujería para hacer el mal, ya fuera en forma de ungüento, como líquido o en polvos:

[...] afirma que existen dos clases de veneno, uno espeso, que se usa como ungüento, y otro líquido. Y se sirven del primero, del espeso, para causar maleficios a la gente, bien obligándola a que lo ingieran, bien vertiendo dicho ungüento sobre su ropa; declara que es tan violento que, con poco que echen en la ropa de alguien, éste sin duda morirá o quedará embrujado por el resto de su vida. (Ibíd.)

La fantasía desplegada por la testigo hacía responsable a dicha sustancia de todo tipo de desgracias, no sólo relativas a la salud y la vida de los seres humanos, sino también al clima y los frutos de la tierra:

En cuanto al líquido, lo introducen en un pequeño tarro de barro que está agujereado por varios lugares en un extremo en forma de regadera, de manera que el ungüento salga por esos agujeros para esparcirlo todo lo que puedan sobre las cosechas. $\mathrm{Y}, \tan$ pronto como se esparce, se forma una nube negra que se hace abrasiva. (Ibíd.)

17 Continuando con su estrambótico relato, la joven relataba cómo los usos del veneno eran diferentes dependiendo del objetivo buscado:

Refiere que ha oído decir a las brujas célebres que dicho veneno tan sólo es válido para estropear toda clase de trigos. Y que, para los demás frutos, como manzanas, peras y bellotas, utilizan otra clase de veneno en polvo que se hace con sapos tostados y secados al fuego que después apilan y convierten en polvo que arrojan en los vapores que se excitan del mar o del monte, y los polvos se mezclan con las nubes. Después, cuando estas nubes se funden en abrasiva y menuda lluvia, ésta daña y echa a perder todos los frutos mencionados. (Ibíd.: 118)

18 Por último, insistiendo en la inmediatez con que las brujas causaban el mal, la muchacha aseguraba que

[...] utilizan además otro veneno líquido y verdoso, que no nos supo decir de qué estaba compuesto, con el que se frotan las manos. Y con solo tocar con ellas la ropa de alguien, este muere o permanece maleficiado o miserable por el resto de su vida. (Ibíd.)

Por detrás de las invenciones inverosímiles destinadas a acusar a ciertas personas de brujas, lo cierto es que el sapo era utilizado comúnmente en la medicina de la época, si bien no para maleficiar sino para curar (Jackson, 2006). Como ha señalado Emma Wilby, la popularidad del sapo como ingrediente médico pudo basarse en el hecho de que este animal sea probablemente la única fuente natural donde se encuentran drogas con 
propiedades analgésicas, calmantes, antibióticas, antivirales y anticancerígenas (Wilby, 2021: 86). La frontera entre los venenos (o ponzoñas) y los productos medicinales de la época era muy sutil. Las mismas plantas y animales benéficos que servían como ingredientes para determinados tratamientos curativos podían convertirse en dañinos, altamente tóxicos e incluso mortíferos utilizados en dosis más altas de lo habitual (Lancre, 2004: 92-93). En el caso de los sapos, no hay que olvidar el componente venenoso y alucinógeno de la bufotenina, un alcaloide contenido en la piel de ciertas especies del género bufo (ibíd.).

Al margen del mayor o menor realismo contenido en las declaraciones acerca del uso de los sapos para envenenar, lo más significativo es la identificación de dichos animales con las acusadas de brujería. Al decir de los testigos, los humildes sapos no sólo servían como almacenes medicinales o venenosos, sino al mismo tiempo como sabios consejeros, por tratarse en realidad de sagaces demonios en miniatura:

[...] las brujas distinguidas habitualmente son asistidas por algún demonio con dos pequeños cuernos en la cabeza, que permanece siempre sobre su hombro izquierdo con forma de sapo. Y únicamente puede ser visto por los que son o han sido brujos.

(Lancre, 2004: 119)

21 En palabras de Jeanette de Belloc, otra joven que también presentó su declaración en Ustaritz - la capital de Labort-, los niños que asistían al sabbat se ocupaban de pastorear rebaños de sapos que servían a los brujos para elaborar sus ponzoñas:

Los niños más jóvenes y las muchachas cuidan con unas pequeñas varas blancas [...] los rebaños del sabbat, formados por una cantidad ingente de sapos que están situados cerca de un arroyo. (Ibíd.)

22 La idea de los rebaños de sapos constituye en sí misma uno de los motivos más impactantes y memorables de la brujería europea. Pero lo que resulta todavía más extraordinario es el hecho de que algunos de dichos sapos se imaginaran vestidos como pequeños hombrecillos. Según el testimonio de María de Yutereguía, una mujer de origen francés juzgada como bruja en el proceso de Zugarramurdi,

[...] estos sapos vestidos son demonios en figura de sapo, que acompañan y asisten a los brujos para inducirlos y ayudar a que comentan siempre mayores maldades. Están vestidos de paño o de terciopelo de diferentes colores, [y el vestido está] ajustado al cuerpo con sólo una abertura que se cierra por lo bajo de la barriga, con un capirote como a manera de capillo, y nunca se les rompe [...]. Y los sapos tienen la cabeza levantada y la cara del demonio [...] y al cuello traen cascabeles y otros dijes. (Mongastón, 1989: 48)

En el relato de la testigo, la antropomorfización de los sapos era llevada al extremo de considerarlos como miembros de la familia con quienes los brujos podrían comunicarse en su mismo lenguaje:

Hanlos de sustentar, y les dan de comer y beber pan, vino y de las demás cosas que tienen para su sustento. Y lo comen llevándolo con sus manos a la boca. Y, si no se lo dan, se lo piden diciendo: «Nuestro amo, poco me regaláis, dadme de comer». Y muchas y diversas veces hablan y comunican con ellos sus cosas. (Ibíd.: 48-49)

El estrecho vínculo entre las brujas y sus sapos personales quedaba representado especialmente en el hecho de alimentarlos como si fueran sus propias criaturas:

Beltrana Fargue refiere que daba el pecho a su sapo, y que algunas veces [este] desde el suelo se alargaba y extendía hasta buscar y tomarla el pecho. $Y$ otras veces en figura de muchacho se ponía en sus brazos para que ella se lo diese. (Ibíd.: 49)

Dichas narraciones rocambolescas constituyen un corpus fantástico único que necesita ser interpretado. Aunque hay quienes lo han atribuido únicamente a la ideología 
persecutoria de los demonólogos, su origen resulta complejo, pues reflejan asimismo la voz de los testigos. La búsqueda de explicaciones para unas declaraciones evidentemente falsas requiere una mirada múltiple. En un terreno liminal entre la consciencia y la inconsciencia, tales relatos pudieron suponer en ocasiones la repetición de determinados estereotipos; otras veces, la invención de ficciones deliberadas siguiendo las sugerencias del juez interrogador; pero en general parecen remitir más bien a ciertas experiencias oníricas o visionarias enraizadas en una cultura ancestral.

El sapo como espíritu familiar, adornado con cintas, alhajas y cascabeles; y colocado en el hombro izquierdo de las brujas para -a la manera de un ángel de la guardia al revés - inspirarles sus fechorías, se emparenta claramente con otras figuras fantásticas del folclore europeo como las hadas, duendes, gnomos, lamias o incluso almas de los muertos (Henderson, 2016). La inserción de motivos de la literatura folclórica en muchos procesos de brujería contra personas de carne y hueso conecta, en un sentido inverso, con el inquietante cuento del príncipe rana recogido y publicado por los hermanos Grimm en 1812. Al igual que en las descripciones de los sapos compinches de las brujas, un sapo -o rana- se convierte aquí en compañero íntimo de una princesa con quien ésta comparte a su pesar juegos, mesa e incluso cama. Pero, mientras en el cuento el repugnante animal esconde un príncipe, en los procesos de brujería su función es encarnar un espíritu demoníaco.

El vínculo establecido entre los sapos y la brujería-maldad femenina se extendió más allá de los extraordinarios procesos por brujería del País $\mathrm{Vasco}^{6}$. Por lo que se refiere a la península ibérica, conservamos pruebas de testimonios procedentes de otras regiones españolas - no tan espectaculares, pero no por ello menos significativos- que muestran cómo uno de los estereotipos más comunes a la hora de acusar a una mujer de bruja era relacionarla con este animal. En algunos casos, las declaraciones de los testigos remitían a ritos particulares en los que dichos animales eran protagonistas, pero en otros se trataba de simples menciones de carácter simbólico.

28 Así, por ejemplo, María Muñoz, apodada «La Taruga» - una auténtica anti-Dulcinea de El Toboso (Toledo) - habría utilizado un sapo para colgarlo con una fina cuerda de cáñamo de una viga de su corral, de forma que las gotas destiladas por la boca del reptil cayeran sobre una zona determinada del suelo. Justamente debajo, la mujer habría enterrado un muñeco de cera con varios alfileres clavados en puntos estratégicos de su cuerpo, como la cabeza, el estómago o el miembro viril. El muñeco representaría al marido de la acusada, enfermo e inválido por su culpa, pues la idea era que, a medida que el sapo se fuera secando, así también se iría secando este, perdiendo vitalidad y, en particular, la capacidad para tener cópula carnal con ninguna otra mujer?

29 Según otros testimonios contenidos en el mismo proceso, la madre de la acusada, queriendo asimismo matar a su yerno, ya que se emborrachaba y maltrataba mucho a su hija, había sido vista con cuatro o cinco sapos en sus manos, los cuales había echado en un recipiente y, tras prenderles fuego, habían salido muchos espumarajos (Cordente Martínez, 1990: 97-98). La acusación de intentar matar al marido mediante hechizos elaborados con sapos se repite en otros procesos de brujería, como el de Catalina Martínez, vecina de Barchín del Hoyo (Cuenca). Según la declaración de su propio esposo contra ella, una prueba incontrovertible de las intenciones criminales de la mujer era que, en la huerta de ambos, él había visto un sapo colgado de un cordel, atado 
por una de sus patas y, bajo su boca, una escudilla para recoger el veneno destilado por el animal ${ }^{8}$.

Dejando a un lado la veracidad de las acusaciones y el realismo de los ritos descritos, lo cierto es que los sapos sirvieron como materialización de la mala voluntad de mujeres señaladas como brujas en una amplia zona geográfica. Así, por ejemplo, en 1571, Esperanza Riba, vecina de Beceite (Teruel), fue acusada de haber enterrado un sapo en su huerto bajo una piedra. En teoría, el animal debía estar envuelto en hilo hilado por la persona a quien se quería dañar, de forma que cuando muriera sería un signo ineludible de la muerte inminente de la víctima. Pero la rea había utilizado hilo hilado por ella, y por eso había tenido miedo de fallecer ella misma en el momento de morir el sapo («Ay, triste de mí, muerta soy»). No obstante, finalmente, su hija habría desenterrado y encontrado vivo al animal una vez librado de su envoltura9.

Cuando no había sapos, se inventaban. Buen ejemplo de ello es el proceso contra Isabel Garay, de Cosuenda (Zaragoza), acusada en 1591 de algo tan impreciso como que en cierta ocasión un testigo llamado Pedro Hernández había notado que de su delantal se le cayó «una cosa a manera de sapo» ${ }^{10}$. Asimismo, otra testigo declaró que, en cierta ocasión, al anochecer, vio que la acusada «sacaba en unos paños colgando una cosa que le parecio a esta deposante sapo» ${ }^{11}$. Y según Juana Llorente, en la lista de sus declaraciones contra la reo, afirmó que una vez que estuvo en su casa hace muchos años,

[...] se asentó en el patio y sintio un ruido en un arca que en dicho patio había.

Y abrió el arca y vio dentro un sapo vivo grande. Y luego volvio a cerrar el arca y cerro la puerta con llave y se fue a su casa alterada de haber visto el sapo, por lo cual la tiene por bruja ${ }^{12}$.

El binomio sapo-bruja llegó a constituir un lugar común tan extendido que su sola mención servía para alertar de la presencia del mal, sin necesidad de justificar nada más. Dicho tópico aparecía de forma más vaga aún en un proceso posterior en el que un testigo aseguró haber visto cómo «saltó un animal a modo de sapo» en casa de Isabel Martínez, juzgada en 1610 por hechicera en la localidad de Borja (Zaragoza) ${ }^{13}$.

III

Resulta interesante comparar la mitología de sapos y murciélagos: dos animales asociados en la literatura mágica desde tiempos inmemoriales hasta la actualidad ${ }^{14}$. Pese a que solían aparecer citados conjuntamente, los primeros representaban lo más rastrero y despreciable y, en consecuencia, la mala intención de las brujas, mientras que los segundos servían como símbolo de la inteligencia atribuida al sexo masculino. De ahí su utilización por hechiceros o magos, no tanto para dañar a terceros, sino con la ilusión de adquirir una serie de poderes extraordinarios que los asimilaran a dichos animales (Charro Gorgojo, 1999 y 2000).

Algunos de los objetivos de los hechizos con murciélagos revelan una suerte de identificación con la naturaleza híbrida de dichos mamíferos, cuya legendaria capacidad para volar y «ver» en la oscuridad los convertía en auténticos héroes del mundo natural. Conviene tener en cuenta que, pese a que en la cultura cristiana los murciélagos fueron progresivamente demonizados, no por ello dejaron de valorarse como representantes simbólicos de la actividad mental y el trabajo intelectual, así como 
de los sacrificios que las largas vigilias de estudio y lectura llevan consigo, robando horas al sueño (Ruiz Bravo-Villasante, 1980).

En la Antigüedad clásica los murciélagos no poseían las connotaciones negativas atribuidas a otras aves nocturnas (como las striges o lechuzas). Por el contrario, su doble naturaleza de cuadrúpedos y aves (la palabra murciélago deriva de mus - ratón- y caeculus -ciego-) los hacía dignos de admiración. Además, por tratarse del único ser alado que pare dos crías, a quienes alimenta con leche de sus ubres y lleva abrazadas al volar, solía destacarse su delicado sentido maternal. En el siglo iv a. C., Aristóteles se refería al amor que el macho murciélago profesaba por la hembra y, en el siglo i d. C., Artemidoro de Efeso escribía que soñar con murciélagos suponía un buen presagio para las embarazadas, pues ellas mismas pronto alimentarían de igual forma a su futuro retoño. Por otra parte, según Homero, la voz chillona pero exigua de dichos animales nocturnos recordaba a los lamentos exhalados por las almas de los muertos en el momento en que Hermes las despertaba con su hermosa vara dorada para a continuación conducirlas al Hades (Macías, 2015).

En el siglo IV d.C., Basilio de Cesarea resaltaba como virtud característica de estos animales su costumbre de pegarse unos a otros formando una especie de racimos, costumbre amorosa que -argumentaba- debería servir de ejemplo a los seres humanos. Ya en la Edad Media, en una fecha tan avanzada como el siglo xIII, Tomás de Cantimpré presentaba a los murciélagos como seres eminentemente comunitarios y sociables, pero también sensibles a los individuos, pues no sólo se agrupaban en racimos sino que, en cuanto uno de ellos se soltaba, el grupo terminaba deshaciéndose. Bien es cierto que dichas virtudes convivían con otros hábitos no tan bien considerados, como su atracción por las tinieblas, pero la definitiva demonización del animal no se produjo hasta más tarde y, aun así, convivió con un poderoso sentimiento de fascinación (Macías, 2015: 164-170).

Prueba de ello es la utilización del murciélago en la heráldica, casi siempre representado con las alas desplegadas. En particular, en la península Ibérica, fue emblema habitual de los blasones de las casas nobiliarias y ciudades de la Corona de Aragón (Tramoyeres Blasco, 1901). Formó parte del antiguo escudo de la ciudades de Barcelona y Palma de Mallorca, siendo aún hoy día la insignia oficial de la ciudad de Valencia debido a una leyenda según la cual un murciélago ayudó al rey cristiano a reconquistar el territorio que estaba en manos de los musulmanes ${ }^{15} . Y$, aunque fuera de la corona de Aragón su presencia no haya sido tan decisiva, todavía se encuentra en algunos escudos, no sólo en Latinoamérica (Santa Fe de Antioquía, en Colombia), sino también en ciertas ciudades europeas como Montchauvet (Francia), Fiefbergen (Alemania) o Brecknockshire (Gales).

La admiración y el rechazo del murciélago coexistieron durante muchos siglos. Pero a finales de la Edad Media empezó a producirse una progresiva demonización de este animal considerado impuro, tal y como se observa en ciertas obras artísticas. Resulta llamativo que, así como en un primer momento el diablo era representado casi siempre con alas de pájaro parecidas a las de los ángeles, y, en el románico, más bien como una animal que se arrastra, a partir de 1210-1225 algunas miniaturas comenzaran a esbozar demonios con alas de murciélago, una iconografía que se extendió en el Occidente gótico en la segunda mitad del siglo XIII (Baltrušaitis, 1983: 153-159).

Fue a partir de entonces cuando los diablos empezaron a concebirse como criaturas que, al igual que los murciélagos, habitaban en rocas abruptas y desplegaban su vuelo 
en cavernas sombrías y profundas ${ }^{16}$. A la demonización definitiva de estos mamíferos se sumó también su contraposición con el blanco pelícano, asociado a la luz y al comportamiento altruista, hasta el punto de actuar como representante simbólico del Redentor, pues se creía que derramaba su sangre para salvar a sus crías. En el otro extremo, los oscuros y nocturnos murciélagos - que a partir del siglo xvIII se asimilaron a los vampiros-, simbolizaban exactamente lo contrario, esto es, el vicio de chupar la sangre de aquellos a quienes herían, provocándoles la muerte (Charbonneau-Lassay, 1997: 559; Fournival, 1990: 60-61).

La fama ambivalente del murciélago continuó persiguiéndolo a lo largo de la Edad Moderna (García Arranz, 1996: 516-518). En la época de las Reformas religiosas sirvió en general como emblema de la ceguera religiosa o moral y, en el bando católico contrarreformista en particular, de la herejía (Alciato, 1993: 98; Cohen, 2008: 41-42). Pero, por otro lado, como animal regido por el planeta Saturno, se le atribuían cualidades que lo relacionaban directamente con el conocimiento profundo y la inspiración artística (Klibansky, Panofsky \& Saxl, 1991). En el célebre grabado dedicado por Alberto Durero a la Melancolía, un murciélago con el hocico abierto, una cola mefistofélica y las alas desplegadas sirve de eco o contrapunto al enigmático personaje principal, también alado, representando quizás su espíritu o doble crepuscular que estaría fuera de su voluntad. El murciélago, que porta una cartela con el título de la obra, es el encargado de desvelar el significado de una escena en la que se expresa la concentración del genio melancólico, que impregna cuanto le rodea con su carácter imaginativo, a un tiempo beneficioso y nefasto (Constantinescu, ${ }^{2012)}$.

La asociación del talento creativo con el temperamento melancólico iba a ser plasmada de nuevo casi dos siglos más tarde por el aragonés Francisco de Goya en uno de sus grabados más célebres. En el capricho número 43, que lleva la leyenda «El sueño de la razón produce monstruos», un individuo dormido - probablemente un autorretrato del mismo pintor, pues ha dejado a un lado los pinceles- se ve acosado por varias figuras amenazantes, entre ellas una bandada de murciélagos. 
Figura 2. - Francisco de Goya, «El sueño de la razón produce monstruos » (Capricho, número 43)

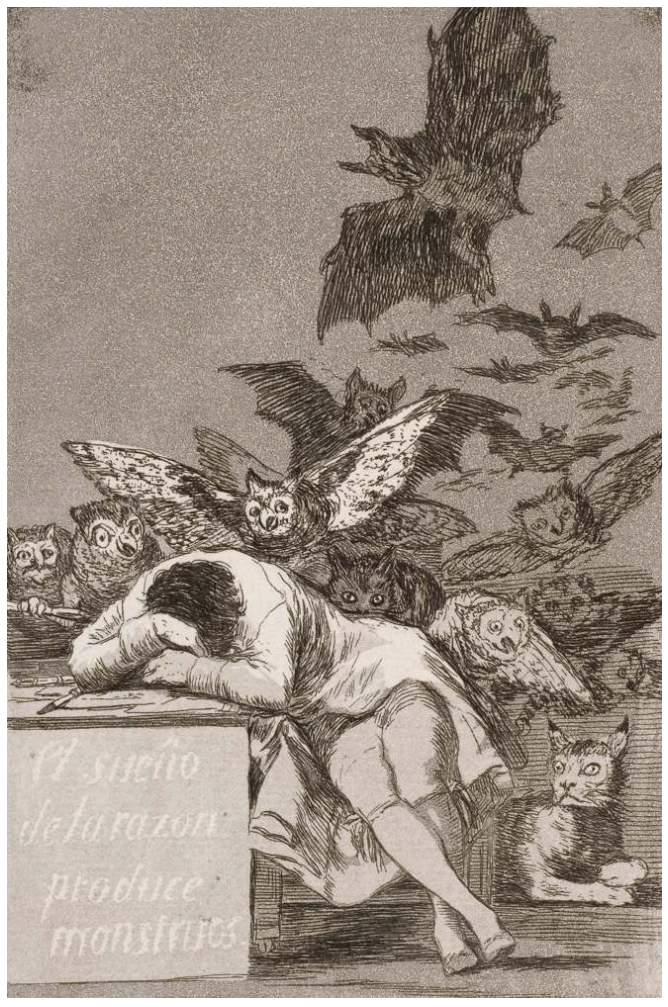

El protagonismo de estos se revela más aún en un dibujo preparatorio de la misma escena, en el que un enorme murciélago está a punto de abalanzarse sobre la figura principal. Aparte de las posibles connotaciones positivas del animal que lo emparentaban con la imaginación creadora, Goya utilizó la figura del murciélago -o, al menos, sus alas- en sus obras como encarnación de lo monstruoso, esto es, del fanatismo religioso y las supersticiones que impedían el avance del racionalismo. Desde el punto de vista del artista, tales actitudes no hacían sino atentar contra el bien común en una España que, a finales del siglo xviII y comienzos del xIX, en muchos aspectos todavía continuaba anclada en la Edad Media.

Teniendo en cuenta la variedad de significados atribuidos al murciélago a lo largo de la Edad Media y Moderna, no sorprende que, al igual que ocurre con el cerdo en el ámbito de lo comestible, prácticamente todas las partes del animal fueran consideradas de provecho, en su caso, como ingredientes mágicos y medicinales destinados a solucionar una amplia gama de problemas. Desde la Antigüedad clásica se conservan testimonios de la utilización de sus alas, su corazón, sus sesos y su cabeza disecada, pero también de su vesícula, su bilis, su grasa, sus excrementos y, sobre todo, su sangre (Ruiz Bravo-Villasante, 1980: 97-99; Macías, 2015: 184-187). Encarnando el espíritu esencial del animal, la sangre de murciélago es mencionada en algunos grimorios y manuscritos de los siglos XIII al XV como componente principal de muchos hechizos, mediante los cuales se buscaba adquirir las habilidades extraordinarias del quiróptero, entre ellas su supuesta aptitud para ver a través de la oscuridad.

A quienes deseaban asegurarse una visión tan aguda por la noche como por el día se les recomendaba untarse los ojos con sangre de murciélago (Kieckhefer, 1992). Y, siguiendo la misma lógica, quienes querían pasar inadvertidos por un tiempo para actuar con total libertad podrían lograrlo recurriendo a la sangre de un animal capaz de fundirse 
con las tinieblas. Adquirir el don de la invisibilidad, tan anhelado por los magos, formaba parte de un ritual religioso elaborado y se valía de la recitación de determinados conjuros - similares a oraciones- que debían ser escritos en latín con sangre de murciélago, y que eran dirigidos a ciertos espíritus demoníacos, pero también a Dios, la Virgen y los ángeles ${ }^{17}$.

Quizás debido a la íntima asociación entre la noche y la sexualidad, la sangre de murciélago era tenida asimismo como un potente afrodisíaco. Según un manuscrito bajomedieval inglés, una forma de provocar deseo carnal en una mujer era empapar una madeja de lana con sangre de murciélago y ponerla debajo de su cabeza mientras dormía (Kieckhefer, 1992: 93). Por otra parte, tal y como afirmaba el médico y teólogo español Arnau de Vilanova, ciertos caracteres escritos con sangre de murciélago, podían acabar con la impotencia de algunos hombres incapaces de mantener relaciones sexuales tras ser víctimas de un embrujamiento (ibíd.: 95).

Aparte de estos y otros usos particulares, la sangre de murciélago, así como el resto de su cuerpo, fue considerada un ingrediente básico en la preparación de círculos mágicos destinados a invocar la ayuda de los demonios para alcanzar todo tipo de objetivos. Según las instrucciones contenidas en ciertos grimorios de los siglos XIII al xV, como el Picatrix ${ }^{18}$ o el Manual de Múnich ${ }^{19}$, los círculos podían trazarse en el suelo con una espada o un cuchillo. Pero también podían ser dibujados en un pedazo de tela o en un trozo de pergamino. $Y$, en ese caso, el material utilizado como tinta solía ser la sangre de un mamífero, a menudo el murciélago. Su carácter siniestro, que lo vinculaba definitivamente al mundo de lo demoníaco, aparece expresado a la perfección en las instrucciones de un manuscrito parisino del siglo xviII en el que se especifica el modo en que debía procederse con dichos animales: «Toma un murciélago y sacrifícalo con tu mano derecha, y con tu mano izquierda saca sangre de su cabeza» (Kieckhefer, 1992: 174).

Aunque la presencia de los murciélagos asociados a los rituales de magia masculina iría decayendo con el tiempo, todavía se encuentran menciones significativas en algunos procesos españoles de la Edad Moderna, como el incoado por el arzobispo de Zaragoza en 1560 contra Juan de la Borda, un sastre bearnés habitante en Fuendetodos (Zaragoza) (Tausiet, 2004: 494-495). El acusado confesó haber utilizado "polvos de murciélago quemado» para lograr diversos fines, entre ellos acceder sexualmente a las mujeres que se le antojara o andar seguro por los caminos sin temor a ser asaltado. De su discurso se deduce la extendida creencia, aún en esas fechas, en el poder de tales animales, cuyo uso ritual debía realizarse coincidiendo con determinadas festividades religiosas. Según la acusación fiscal que figura al inicio de su proceso, incoado a comienzos del mes de enero,

La noche de Navidad más cerca pasada, con diabólico espíritu [el reo] puso en el altar mayor de la iglesia de dicho lugar donde se había de decir la Misa del Gallo, debajo de los corporales, encima de la lápida, unos polvos de murciélago quemado [...] para hacer con ellos hechicería e invocación del diablo ${ }^{20}$.

En su interrogatorio, el reo no negó la acusación, aunque sí cargó buena parte de su responsabilidad sobre un estudiante francés llamado Pierre. Según el sastre, este joven le había vendido un documento o cédula por dieciocho reales gracias al cual «alcanzaría cualquier mujer que quisiese $»^{21}$. Y que, asimismo, el estudiante le había aconsejado que, para ir seguro por los caminos sin miedo a ser robado, 
[...] tomase un murciélago y lo secase al fuego y lo hiciese polvos, y lo pusiese en la lápida [del altar], debajo del cáliz donde han de consagrar la misa, y después llevase aquellos polvos consigo ${ }^{22}$. en Fuendetodos donde hay muchos murciélagos para tomar de ellos». Sin embargo, no habiendo podido cazar ninguno, decidió encargarle a otro francés llamado Bernard de la Micet Gascón que fuese él quien obtuviera, al menos, uno de estos animales. Bernard consiguió atrapar a uno de los murciélagos y se lo llevó al sastre quien «lo hizo polvos al fuego, como le había dicho el estudiante y tomó los polvos y los puso en un papel». Una vez hecho el envoltorio, el sastre entró a la iglesia de la localidad y se dirigió al altar «con intención de poner los dichos polvos en la lápida del Santísimo Sacramento». Pero, según su relato, tampoco aquella vez pudo lograr su objetivo, ya que, al sentirse observado por los feligreses, «volviose atrás sin llegar al altar». Sin desfallecer, volvió a intentarlo por tercera vez, pidiéndole esta vez al monaguillo del párroco que le ayudara, y prometiéndole «que le daría cuatro reales» si el muchacho depositaba los polvos debajo del altar durante la celebración de la Misa de Gallo. En su propio descargo, el reo confesó no saber si el muchacho los había puesto o no ${ }^{23}$.

Sea como fuere, lo que resulta indudable es la fe inquebrantable del acusado en los poderes mágicos de los murciélagos, así como en la posibilidad de incorporarlos mediante determinadas ceremoniales. A mediados del siglo xvI, la Iglesia había decidido castigar este tipo de creencias y los rituales asociados a ellas. Como se lee en este proceso, siguiendo un goyesco itinerario, el sastre francés fue preso en la cárcel de Fuendetodos, de donde consiguió escapar, llegando a pie hasta la Puebla de Albortón. Pero, una vez allí, el alcalde de la localidad volvió a encarcelarlo y a continuación lo envió a Zaragoza para ser juzgado por su arzobispo. Resulta interesante que a diferencia del escepticismo con que los tribunales diocesanos estaban contemplando la mayoría de las acusaciones de brujería por estas fechas- el reo fuera considerado un auténtico criminal, culpable del delito de nigromancia. Como consecuencia, en su sentencia fue condenado a recibir cien azotes a lo largo de un recorrido «por los lugares públicos y acostumbrados» de la ciudad, tras los cuales debía ser expuesto a la vergüenza pública junto a la catedral:

[...] en una escala a la puerta de La Seo, con una coroza en la cabeza y mantela vestida, la cual denote su delicto, para que para él sea castigo y para los otros ejemplo ${ }^{24}$.

51 Además, se lo desterró perpetuamente tanto de la ciudad de Zaragoza como del resto de la diócesis, bajo amenaza de sufrir un castigo doble de doscientos azotes en caso de volver sobre sus pasos.

Pese a los intentos de los jueces eclesiásticos por acabar con la magia ritual de invocación a los demonios, son abundantes los documentos que testifican su vigencia a lo largo del tiempo. Buen ejemplo de la duradera esperanza puesta en las virtudes de los murciélagos es un proceso llevado a cabo por la Inquisición en 1608 contra otro francés que vivía en Bordón (Teruel). El reo fue denunciado al Santo Oficio por haberle dicho a un vecino suyo que, si quería tener un demonio familiar, fuera con él a un lugar cerca del pueblo donde pudieran oírse las campanas de la iglesia, y que allí,

[...] tomase un murciélago. Y al primer toque del Ave María, había de degollar al murciélago y hacer ciertas letras y círculos con la sangre, e invocar a los demonios. Y se le aparecerían los demonios en un caballo, y podría pactar [...] lo que quisiese ${ }^{25}$. 
La fantasía masculina de adquirir una extensa gama de poderes extraordinarios a través de los murciélagos no se limitaba a la visión nocturna, la invisibilidad, la protección frente a posibles ataques o la satisfacción del amor carnal. Uno de los objetivos más comunes de la magia practicada por varones era conseguir riquezas materiales $\sin$ mediar esfuerzo, casi siempre mediante la búsqueda de tesoros ocultos (aunque, irónicamente, los rituales elaborados para encontrarlos implicaran a menudo mucho trabajo). Otra forma fácil de conseguir riqueza sería ganar al juego, un sueño que se materializaba en la confección de ciertos hechizos pensados para dar suerte a quienes los llevaran consigo (Tausiet, 2007).

Tales prácticas se transmitieron al otro lado del Atlántico, en las colonias americanas. Un testimonio inquisitorial revela que en 1772 un soldado alemán llamado Agustín Kelin -que había desembarcado en Veracruz en 1764- solía aconsejar a sus compañeros de batallón que, si querían ganar al juego, lo que debían hacer era fabricarse talismanes y colocarlos bajo un altar durante la celebración de, al menos, tres Misas. Y, en cierta ocasión, ante el fracaso de un amuleto, Kelín insistió en que había que incorporarle el corazón de un murciélago, el cual debía llevar el interesado colgado al cuello a modo de reliquia (Cruz Martínez, 2018: 112-114).

Volviendo al mundo de la brujería femenina, resulta evidente que sapos y murciélagos, por las connotaciones de género, sirvieron como representantes de dos formas opuestas de entender la magia: dañina, en el caso de los primeros, y potenciadora de virtudes ambivalentes, en el caso de los segundos. No obstante, ambos animales compartían, según el saber de la época, un importante rasgo que los hacía intrínsecamente semejantes. En su célebre tratado sobre la naturaleza oculta de las cosas, Enrique Cornelio Agrippa clasificaba a los sapos «entre los reptiles», y a los murciélagos «entre las aves», pero tanto unos como otros aparecían situados bajo la decisiva influencia de Cronos (Agrippa, 1992: 119-120). Ello implica que, a su manera, las dos especies encarnaban dos facetas diferentes de la inspiración creadora característica de los seres contemplativos, melancólicos y nocturnos. Sin duda, el carácter extraño, enigmático y evasivo de ambos animales -tan difíciles de atrapar como los propios pensamientos- no podía materializar mejor la naturaleza esquiva de la magia.

\section{BIBLIOGRAFÍA}

AGRIPPA Enrique Cornelio (1992), Filosofía oculta: magia natural, Madrid: Alianza.

AlCiATo Andreæ (1993), Emblemas, ed. de Santiago Sebastián, Madrid: Akal.

Alighieri Dante (1988), Divina Comedia, ed. de Giorgio Petrocchi y Luis Martínez de Merlo, Madrid: Cátedra.

BALTRUŠAITIS Jurgis (1983), La Edad Media fantástica. Antigüedades y exotismos en el arte gótico, Madrid: Cátedra. 
Benito RuAno Eloy (1995), A Toledo los diablos, Cuenca: Universidad de Castilla-La Mancha. BREUER Heidi (2009), Crafting the Witch: Gendering Magic in Medieval and Early Modern England, Londres: Routledge.

CARo BARoja, Julio (1961), Las brujas y su mundo, Madrid: Revista de Occidente.

CoHEN Simona (2008), Animals as Disguised Symbols in Renaissance Art, Leiden y Boston: Brill. Constantinescu Doina (2011), «El infinito simbólico de la metáfora poética. Alberto Durero. Melencolia 1», Disertaciones, 2, 1-29.

CORDENTE MARTínEz Heliodoro (1990), Brujería y hechicería en el obispado de Cuenca, Cuenca: Diputación de Cuenca.

Charbonneau-Lassay Louis (1997), El Bestiario de Cristo. El simbolismo animal en la Antigüedad y la Edad Media, Palma de Mallorca: José J. de Olañeta.

CHARRO GORGOJO Manuel Ángel (1999), «Murciélagos: príncipes de las tinieblas», Revista de Folklore, 19(220), 111-118.

CHARRO GORGOJO Manuel Ángel (2000), «Sapos: historia de una maldición», Revista de Folklore, 20(235), 20-32.

CHARUTY Giordana (1997), Folie, mariage et mort. Pratiques chrétiennes de la folie en Europe occidentale, Paris: Seuil.

DE GRAAF Robert M. (1991), The Book of the Toad: A Natural and Magical History of Toad-Human Relations, Cambridge: Lutterworth.

DE MARTINO Ernesto (1999), La tierra del remordimiento, Barcelona: Bellaterra.

DELPECH François (1993), «La "marque” des sorciéres : logique(s) de la stigmatisation diabolique», N. Jacques-Chaquin \& M. Préaud (edd.), Le sabbat des sorciers, XV-XVIII siécles, Grenoble : Jérôme Millon, 347-368.

FouRnIVAl Richard de (1990), Bestiario de Amor, Madrid: Miraguano.

FURST Peter T. (1980), Los alucinógenos y la cultura, México: FCE.

GARCíA ARRANZ José J. (1996), Ornitología emblemática. Las aves en la literatura simbólica ilustrada en Europa durante los siglos XVI y XVII, Cáceres: Universidad de Extremadura.

GARI LACRUZ Ángel (1989), El uso de las drogas en la brujería y algunos relatos de magia, Zaragoza: Socidrogalcohol.

GARI LACRUZ Ángel (1991), Brujería e Inquisición en el Alto Aragón en la primera mitad del siglo XVII, Zaragoza: Diputación General de Aragón.

GinZBURG Carlo (1991), Historia Nocturna, Madrid: Muchnik.

GoLDEN Richard M. (ed.) (2006), Encyclopedia of Witchcraft. The Western Tradition (vol. 4), Santa Barbara: ABC-Clio.

GRILLOT DE GIVRY Émile-Jules (1991), El museo de los brujos, magos y alquimistas, Barcelona: Martínez Roca.

HENDERSON Lizanne (2016), Witchcraft and Folk Belief in the Age of Enlightenment Scotland, 1670-1740, Basingstoke: Palgrave Macmillan. 
HENNINGSEN Gustav (2010), El abogado de las brujas: brujería vasca e Inquisición española, Madrid: Alianza Editorial.

IDOATE Florencio (1975), «Los brujos del valle de Araiz», Brujología. Congreso de San Sebastián. Ponencias y comunicaciones, Madrid: Seminarios y Ediciones, 53-68.

JACKSON W. Andrew (2006), «The Role of Toads and Frogs in Medicine», Farmaceutical Historian, $36(2), 31-36$.

Kezich Giovanni \& SePPILli Tullio (edd.) (2001), Saperi terapeutici tradizionali dell' arco alpino, San Michele all' Adige: Museo degli usi e costumi della gente trentina.

KIECKHEFER Richard (1992), La magia en la Edad Media, Barcelona: Crítica.

KIECKHEFER Richard (1998), Forbidden Rites: A Necromancer's Manual of the Fifteenth Century, Pennsylvania: The Pennsylvania State Press.

KLIBANSKY Raymond, PANOFSKY Erwin \& SAXL Fritz (1991), Saturno y la melancolía, Madrid: Alianza Editorial.

LANCRE Pierre de (2004), Tratado de brujería vasca. Descripción de la inconstancia de los malos ángeles y demonios, ed. Elena Barberana, Tafalla: Txalaparta.

LE ROY LADURIE Emmanuel (1988), Montaillou, aldea occitana, de 1294 à 1324, Madrid: Taurus.

LE ROY LADURIE Emmanuel (1984), La bruja de Jasmin, Barcelona: Argos Vergara.

LÉVI-STRAUSS Claude (1962), Le totémisme aujourd'hui, Paris: Presses universitaires de France.

LEVACK Brian P. (2013), Gender and Witchcraft: New Perspectives on Witchcraft, Magic, and Demonology, Londres: Routledge.

MACíAs Cristóbal (2015), «Simbolismo, astrología y magia: el caso del murciélago», Calamvs renascens, 17, 161-188.

MANDROU Robert (1968), Magistrats et sorciers en France au XVII siècle : une analyse de psychologie historique, Paris: Plon.

MongaSTón Juan de (1989), Proceso a la brujería. En torno al Auto de Fe de los brujos de Zugarramurdi, Logroño, 1610, ed. Manuel Fernández Nieto, Madrid: Tecnos.

MONTER William (1997), «Toads and Eucharists: The Male Witches of Normandy, 1564-1660», French Historical Studies, 20(4), 563-595.

PIzZA Giovanni (1998), «The Virgin and the Spider: Revisiting Spirit Possession in Southern Europe», C. Papa, G. Pizza \& F. M. Zerilli (edd.), Incontri di Etnologia Europea / European Ethnology Meeting, Nápoles: Edizioni Scientifiche Italiane, 49-81.

PIzZA Giovanni (2001), «Il motivo del rospo-uttero: Stregoneria, possessione e metafore del corpo femminile nelle opere dei folkloristi dall' Alsazia alle Alpi orientali», G. Kezich \& T. Seppilli (edd.), Saperi terapeutici tradizionali dell' arco alpino, San Michele all' Adige: Museo degli usi e costumi della gente trentina, $74-84$

QUEVEDo Francisco de (1972), Sueños y discursos, ed. Felipe C. R. Maldonado, Madrid: Castalia. RODRíGUEZ CACHO Lina (2012), «Ciertas enemigas de Quevedo: las batracias y las hembrilatinas», La Perinola: Revista de investigación quevediana, 16, 77-95.

RuIz BRAVo-VILLASANTE Carmen (trad. y ed.) (1980), Libro de las utilidades de los animales, Madrid: Fundación Universitaria Española. 
SCHNEIDER Marius (1998), El origen musical de los animales-símbolos en la mitología y la escultura antiguas, Madrid: Siruela.

TAUSIET María (2004), Ponzoña en los ojos. Brujería y superstición en Aragón en el siglo XVI, Madrid: Turner.

TAUSIET María (2007), Abracadaba Omnipotens. Magia urbana en Zaragoza en la Edad Moderna, Madrid: Siglo XXI.

Tramoyeres Blasco Luis (1901), «Lo Rat Penat en el escudo de armas de Valencia», Boletín de la Real Academia de la Historia, 38, 438-445.

VIDAL R. Benito (2001), Personajes míticos del Reino de Valencia, Barcelona: Abraxas.

WILBY Emma (2021), Invoking the Akelarre: Voices of the Accused in the Basque Witch-craze, 1609-1614, Eastbourne: Sussex Academic Press.

XochiqueTZALli Cruz Martínez (2018), Magia animalística novohispana: la pervivencia de algunos usos mágicos y simbólicos medievales de ciertas bestias en narraciones inquisitoriales del siglo XVIII (Tesis doctoral), Universidad Autónoma de México, <http://tesiuami.izt.uam.mx/uam/aspuam/ presentatesis.php?recno=122607\&docs=UAMII122607.pdf>.

\section{NOTAS}

1. «All the charms of Sycorax-wilby toads, beetles, bats-light on you!» (W. Shakespeare, The Tempest (1609-1610), I, II, 339-340).

2. «Round about the cauldron go, / In the poisoned entrails throw. / Toad, that under cold stone / Days and nights has thirty-one/ Swelter'd venom sleeping got,/ Boil thou first i' th' charmed pot» (W. Shakespeare, Macbeth (1606), IV, I, 4-9).

3. El término tótem deriva de la palabra ototeman (en el lenguaje algonkina de los Ojibwa, pueblo indígena de América del Norte) y significa: «es de mi parentela». La raíz gramatical «ote» indica la relación de sangre entre los hermanos que tienen la misma madre y que no pueden casarse entre ellos (Lévi-Strauss, 1962).

4. El motivo de la marca de sapo en el ojo aparecía ya mencionado en el proceso de los brujos de Ituren en 1525 (Idoate, 1975).

5. Se trata de un panfleto que el impresor Juan de Mongastón editó en 1611 sobre el Auto de Fe de Logroño de 1610, que incluye una relación dedicada a los actos y crímenes de los brujos/as juzgados los días 7 y 8 de noviembre de ese mismo año.

6. Buen ejemplo de ello es su presencia en Normandía, donde se constataron ritos según los cuales algunos sapos eran alimentados con hostias consagradas (Monter, 1997).

7. Proceso contra María Muñoz, «La Taruga», Archivo Diocesano de Cuenca, Leg. 460, Exp. 6335 (Cordente Martínez, 1990: 97).

8. Proceso contra Catalina Martínez, Archivo Diocesano de Cuenca, Leg. 464, Exp. 6364 (Cordente Martínez, 1990: 98).

9. Proceso contra Esperanza y Gaspara Riba, Beceite, 1571, Archivo Diocesano de Zaragoza,

C. $27-11$, fols. $15 r$ y $v$.

10. Proceso contra Isabel Garay, Cosuenda (Zaragoza), 1591, Archivo Diocesano de Zaragoza,

C. $33-23$, fol. 2 .

11. Ibíd., fol. $85 v$.

12. Ibíd., fol. $92 r$.

13. Proceso contra Isabel Martínez, Borja (Zaragoza), 1610. 
14. Un ejemplo de la presencia literaria de ambos animales -rescatados de la magia para asociarlos a un sexo explícito y provocativo- es la novela Trópico de Cáncer (1934) de Henry Miller («You can stuff toads, bats, lizards up your rectum»: «Puedes embutirte el recto con sapos, murciélagos, lagartos»).

15. La presencia del murciélago en el escudo de Valencia se explica por una leyenda referida a una profecía según la cual, mientras un murciélago volara por las noches, el reino de Valencia se mantendría bajo poder musulmán. Por eso, estando el rey Jaime I de Aragón (1208-1276) acampado con sus tropas fuera de las murallas de la ciudad, cuando un murciélago hizo nido en lo alto de su tienda real, el rey ordenó que no lo matasen pues podía ser un buen augurio. De hecho, una noche, mientras todos dormían, se oyó un extraño sonido cerca de la tienda del rey. Las tropas se pusieron en guardia pues el ejército musulmán se hallaba muy cerca del campamento para atacar por sorpresa. Una vez terminada la batalla, el rey vencedor quiso conocer el origen del misterioso sonido que había alertado a su ejército, permitiendo así hacer frente a los enemigos y descubrieron que el murciélago había estado golpeándose a sí mismo en un tambor hasta despertarlos. En agradecimiento al animal, Jaime I ordenó colocar al murciélago en la parte más alta del escudo de Valencia y en su yelmo de guerra (Vidal, 2001).

16. En Italia, Giotto los representó de este modo en el fresco en que San Francisco expulsa a los demonios, situado en la iglesia superior de Asís. Y en su Divina Comedia («Inferno», canto XXXIV, 46-51) Dante imagina a Lucifer con tres caras (roja, amarila y negra, parodiando la Trinidad) y dos enormes alas de murciélago: «Bajo los tres [rostros] salían un gran par de alas, / tal como convenía a tanto pájaro: / velas de barco no vi nunca iguales. / No eran plumosas, sino de murciélago / su aspecto; y de tal forma aleteaban, / que tres vientos de aquello se movían» (Dante Alighieri, 1988: 284).

17. Un ejemplo de dichos conjuros-oraciones, traducido del latín al español es el siguiente: « $\mathrm{Oh}$ tú, Pontation, maestro de la invisibilidad, con tus maestros Tenem, Musach, Motagren, Bries Domedis, Ugemal, Abdita, Patribisib, Tangadentet, Ciclap, Clinet, Succentat, Collegid, Bereit y Plintia, Gastaril y Oletel. Yo te conjuro Pontation y a estos mismos maestros de la invisibilidad, por aquel que hace temblar el universo, por el cielo y la tierra, los querubines y los serafines, y por aquel que ha hecho engendrar a la Virgen, y que es Dios con el hombre, a que pueda realizar este experimento con perfección, de manera que a la hora que yo quiera pueda ser invisible. De nuevo te conjuro, así como a tus ministros, por Stabuches y Nechaerom, Esey, Enitgida, Bellis, Simonei, a que vengas de inmediato con tus dichos ministros y lleves a cabo esta obra como vosotros sabéis hacerlo. Y que este experimento me haga invisible, de tal manera que nadie me vea, ¡Amén!» (Givry, 1991: 180-182).

18. El Libro de Picatrix es un tratado de magia talismánica escrito en árabe en España en el siglo XI y traducido al latín y el castellano en torno a 1256 durante el reinado de Alfonso X el Sabio. La versión latina se difundió por todo Occidente y alcanzó un notable éxito entre los siglos XV y XVIII (Benito Ruano, 1995).

19. Se trata de un grimorio manuscrito en latín, que fue escrito en el siglo $\mathrm{xv}$, y que se conserva en la Biblioteca Estatal de Baviera (Múnich) (Kieckhefer, 1992: 14). El manuscrito en cuestión es Clm 849, Bayerische Staatbibliothek, Munich, fols. 3r-108v. Richard Kieckheffer dedicó un libro completo a estudiar este documento (Forbidden Rites: A Necromancer's Manual of the Fifteenth Century, Pennsylvania, The Pennsylvania State Press, 1998).

20. Proceso contra Juan de la Borda, Fuendetodos (Zaragoza), 1560, Archivo Diocesano de Zaragoza, C. 52-12, fol. 3.

21. Ibíd., fol. $7 r$.

22. Ibíd., fol. $7 v$.

23. Ibíd., fol. $8 r$.

24. Ibíd., fol. $9 v$. 
25. Relación de causa contra Pedro Cortés, Bordón (Teruel), 1608, Archivo Histórico Nacional, Sección Inquisición, Libro 990, fols. 556v-557r.

\section{RESÚMENES}

Dos de los animales mencionados más frecuentemente en los procesos de brujería españoles de la Edad Moderna son los sapos y los murciélagos. En los siglos XVI y XVII los primeros se asociaban fundamentalmente a las mujeres (brujas) y los segundos a los hombres (magos o hechiceros). Esta distinción, aparentemente casual, basada en prácticas reales, pero sobre todo en significados simbólicos, revela una indudable aproximación de género al mundo de la magia.

Además de analizar las fantasías relativas a los sapos vestidos mencionados en el célebre proceso por brujería que tuvo lugar en Zugarramurdi a comienzos del siglo XVII, veremos otros ejemplos de la utilización de sapos por mujeres en la península Ibérica como ingredientes para sus hechizos. En contraste con el carácter maléfico asociado a la brujería femenina, el uso de murciélagos por parte de los varones acusados de nigromancia apunta a una visión positiva de la magia, entendida más bien como un arte o ciencia capaz de hacer posible lo imposible.

Two of the animals more frequently mentioned in Early Spanish witch-trials are toads and bats. However, unlike the usual representations of them together in modern popular culture, toads were fundamentally associated with women (witches) and bats with men (wizards). This apparently casual distinction, based on actual practices but above all on old symbolic meanings, reveals a dramatic gendered approach to magic, as well as to the values and drawbacks of it.

In addition to analysing the fantasies concerning toads that wear clothes, the familiar demons of the well-known trial of Zugarramurdi (Navarre), I will present examples of the use of toads from elsewhere in the Spanish peninsula as ingredients in spells almost always attributed to women. In contrast to the maleficent character associated with female witchcraft and toads, the use of bats by men accused of necromancy indicates a positive connotation of magic, understood as a higher art or science capable of making possible the impossible.

Les deux animaux les plus fréquemment mentionnés dans les procès de sorcellerie espagnols de l'époque moderne sont les crapauds et les chauves-souris. Aux $\mathrm{XVI}^{\mathrm{e}}$ et $\mathrm{XVII}^{\mathrm{e}}$ siècles, on associait fondamentalement les premiers aux femmes (sorcières) et les seconds aux hommes (magiciens et sorciers). Cette distinction, apparemment fortuite, mais fondée sur des pratiques réelles et surtout sur des significations symboliques, révèle le caractère genré du monde de la magie.

Nous analyserons l'imaginaire relatif aux crapauds habillés dans le célèbre procès de sorcellerie de Zugarramurdi au début du XVII ${ }^{\mathrm{e}}$ siècle, et nous verrons d'autres exemples de l'utilisation des crapauds par les femmes en guise d'ingrédients pour leurs sortilèges dans la péninsule Ibérique. À l'opposé du caractère maléfique associé à la sorcellerie féminine, l'utilisation de chauves-souris par les hommes accusés de nécromancie tend vers une vision positive de la magie, considérée comme un art ou une science pouvant rendre possible l'impossible. 
ÍNDICE

Palabras claves: brujería, magia, animales, símbolos, sapos, murciélagos, género

Mots-clés: sorcellerie, magie, animaux, symboles, crapauds, chauves-souris, genre

Keywords: witchcraft, magic, animals, symbols, toads, bats, gender

\section{AUTOR}

MARÍA TAUSIET

Université de Valence

mariatausiet@gmail.com 